\title{
ФИЗИКО-МЕХАНИЧЕСКИЕ СВОЙСТВА КЕМБРИЙСКИХ ГЛИН СЕВЕРНОЙ ЭСТОНИИ
}

Глинистые породы нижнего кембрия представляют верхний этаж коренного ложа во многих городах предглинтовой низины республики, ввиду чего крупные строительные объекты очень часто врезаются в эти породы. Поэтому изучение физико-механических параметров строительного основания данного типа имеет важное значение. К сожалению, опубликованный до сих пор материал по этому вопросу весьма скуден (Olli, 1962). Однако к настоящему времени в Әстонии уже накопился достаточный опыт по проектированию и строительству на кембрийские глины, а в лабораториях ГПИ «Эстпромпроект» и «Әстонпроект» проведены многочисленные испытания, позволяющие подвести некоторые итоги и сделать обобщения. Ниже представляется обобщенный материал по основным физико-механическим свойствам кембрийских глин Северной Эстонии, изученным в последние годы по единой методике (частично и одним из авторов) .

Как известно, кембрийские отложения, выходящие перед глинтом, представлены сверху алевролитами тискреской свиты, а затем преобладающими глинами люкатиской и лонтоваской свит (Менс, Пиррус, 1977). При этом глинистые толщи существенно различаются между собой. В верхней, люкатиской свите мощностью до 20 м глины зеленоватосерого цвета образуют более выдержанные пласты $(1-3$ м) лишь в нижней части разреза. В остальной части свиты регулярно встречаются крепкосцементированные прослои алевролитов, которые придают породам специфические свойства и значительно уменьшают при этом значения характеристик, свойственных глинистым породам. Однако наиболее верхние слои люкатиской свиты являются, как правило, водоупором для грунтовых вод, циркулирующих в вышележащих отложениях, и поэтому нередко сильно разжижены и вторично разуплотнены. Такие слои требуют при проектировании особого внимания, и в настоящей работе данные по основным их свойствам приведены отдельно от данных по остальной части свиты.

Нижележащая, лонтоваская свита представлена толщей однородных глин мощностью $70-80$ м. Прослои песчаников появляются лишь в самых низах ее (сямиская пачка), находящихся на глубине 60-100 м, и поэтому редко соприкасаются со строительными объектами. Однако западнее Локса, в верхней части (первые метры) свиты (таммнеэмеская пачка) проявляются также единичные прослои крепкосцементированных алевролитов, которые сближают эту часть разреза с отложениями люкатиской свиты и приводят к заблуждению при разграничении этих двух свит. Основная, средняя часть лонтоваской свиты (50-60 м) представлена 
однородными сравнительно высокодисперсными глинами. Верхняя, кестлаская пачка характеризуется преимущественно фиолетово-пестроокрашенными глинами, нижняя, махуская - зеленовато-серыми более алевритовыми глинами. Из-за отсутствия отчетливой слоистости и прослоев пород другого состава глинистая толща лонтоваской свиты - собственно «синие глины» - обладает большой выдержанностью основных физикомеханических параметров как по вертикали, так и по латерали.

Из сказанного следует, что при инженерно-геологических изысканиях весьма важно разграничивать обе вышеотмеченные свиты. Это не всегда легко, ибо пограничный конгломерат из фосфатизированных галек встречается не повсеместно (Лоог и др., 1966; Менс, Пиррус, 1975). В восточных районах республики надежным критерием служит кровля пестроокрашенных глин кестлаской пачки, которая располагается обычно на 0,5-2,0 м ниже подошвы люкатиской свиты. В западных районах следует пользоваться палеонтологическими данными: заменой руководящих окаменелостей Platysolenites в лонтоваской свите остатками Volborthella в люкатиской свите, а также исчезновением изобилия пиритизированных ходов илоедов при смене лонтоваской свиты люкатиской. Другие особенности строения рассматриваемых свит в настоящее время достаточно освещены в литературе (Pirrus, 1973; Менс, Пиррус, 1977).

Гр анулометрический состав лонтоваских глин довольно однороден. При обобщении данных 286 гранулометрических анализоз, выполненных путем дезинтеграции пород обычно применяемыми в инженерной геологии методами, выявлено, что в составе изученных отложений явно превалирует фракция $0,05-0,002$ мм, в $57-64 \%$ случаев (табл. 1). При этом частицы размером 0,01-0,002 мм преобладают над

Таблица 1

\section{Гранулометрический состав и основные физические свойства кембрийских глин}

\begin{tabular}{|c|c|c|c|c|c|c|c|c|c|c|}
\hline \multirow[b]{2}{*}{ Глины } & \multirow[b]{2}{*}{ 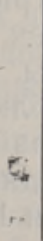 } & \multicolumn{4}{|c|}{ Содержание фракции, \% } & \multirow{2}{*}{ 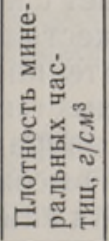 } & \multirow[b]{2}{*}{ 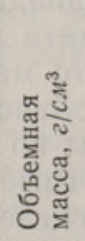 } & \multirow{2}{*}{ 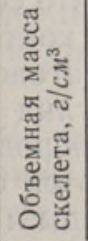 } & \multirow{2}{*}{ 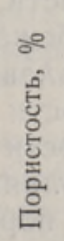 } & \multirow[b]{2}{*}{ 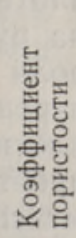 } \\
\hline & & $\begin{array}{l}2 \\
0 \\
0 \\
1 \\
1 \\
\text { N }\end{array}$ & $\begin{array}{l}0 \\
0 \\
0 \\
1 \\
10 \\
0 \\
0 \\
0\end{array}$ & $\begin{array}{l}\text { oै } \\
0 \\
\text { i } \\
\text { i } \\
\vdots \\
0\end{array}$ & 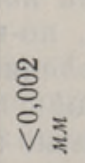 & & & & & \\
\hline
\end{tabular}

\section{Люкатиская свита}

Разуплотненные

выветрелые

$\begin{array}{ccrrrrrrrr}\bar{x} & 12,0 & 32,2 & 24,7 & 31,1 & 2,73 & 2,03 & 1,68 & 38,3 & 0,63 \\ \text { мин. } & 0 & 15,0 & 5,2 & 9,5 & 2,69 & 1,74 & 1,35 & 28,1 & 0,39 \\ \text { макс. } & 48,1 & 52,7 & 39,2 & 54,1 & 2,75 & 2,23 & 1,97 & 50,9 & 1,04 \\ \bar{x} & 16,2 & 33,2 & 22,0 & 28,6 & 2,74 & 2,18 & 1,89 & 31,1 & 0,46 \\ \text { мин. } & 0 & 2,3 & 2,4 & 7,0 & 2,64 & 1,91 & 1,59 & 19,4 & 0,24 \\ \text { макс. } & 68,0 & 59,4 & 50,9 & 49,3 & 2,94 & 2,39 & 2,21 & 43,0 & 0,68\end{array}$

Лонтоваская свита

$\begin{array}{lccrrrrrrrr}\text { Неизмененные } & \bar{x} & 6,4 & 24,8 & 35,2 & 33,6 & 2,75 & 2,24 & 1,96 & 29,5 & 0,42 \\ & \text { мин. } & 0 & 0,1 & 2,8 & 11,0 & 2,66 & 1,95 & 1,52 & 19,0 & 0,20 \\ & \text { макс. } & 53,5 & 61,6 & 63,7 & 54,4 & 2,88 & 2,39 & 2,26 & 43,0 & 0,82\end{array}$

частицами 0,05-0,01 мм. Песка во всех пробах менее $10 \%$ и он представлен лишь мелкозернистой фракцией или аутигенными образованиями (агрегатами пирита и глауконита). Следовательно, глины лонтоваской свиты, по усовершенствованной классификации Н. Н. Охотина (Ломтад- 
зе, 1970), могут быть рассмотрены как собственно глины $(70,8 \%)$ или суглинки $(29,2 \%)$.

Присутствие в глинах люкатиской свиты значительного количества рассеянного алевритового и песчаного материала обусловливает большую гранулометрическую изменчивость этих глин (табл. 1). Глинистой фракции в них в среднем на $5 \%$ меньше, а грубозернистой $(>0,05$ мм) на $9 \%$ больше, чем в лонтоваских глинах. Таким образом, они чаще всего соответствуют суглинкам или даже супесям. Четкой направленности в изменениях дисперсности глин в региональном плане не наблюдается.

Плотность минеральных частиц лонтоваских глин меняется в очень узких пределах, что хорошо согласуется с данными о постоянстве минерального состава глинистой фракции этих пород в разрезах (Пиррус, 1970).

Изменения в плотности минеральных частиц люкатиской свиты более значительны, что объясняется их составом: глины люкатиской свиты содержат кластогенные зерна кварца, пирита, глауконита и др. минералов больше, чем глины лонтоваской свиты. Процессы последующего гипергенеза мало изменили первичный минеральный состав этих глин, о чем свидетельствует близкое среднее значение плотности как

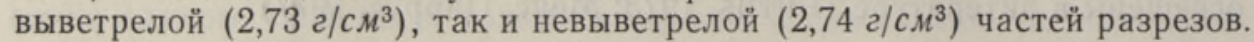

Объемная масса и объемная м асса скелета лонтоваских глин указывают на значительную уплотненность их, что обусловлено нагрузкой вышележащих толщ, достигающей, по расчетам В. Д. Ломтадзе (1958), 6-7 MПа в течение полумиллиарда лет. Однако пределы изменения крайних значений объемной массы и объемной массы скелета довольно широки, что говорит о значителыной изменчивости локальных условий постседиментационного уплотнения глины.

Существенного различия по плотности между глинами предглинтовой низины и более южных районов не наблюдается. В некоторых разрезах (Нарва) на глубине около 70 м отмечается скачкообразное увеличение п.лотности, что совпадает с изменением гранулометрического состава глин на рубеже контакта кестлаской и махуской пачек, т. е. с увеличением роли алевритового материала ниже этой границы. Изменениями в дисперсности глин объясняется, по-видимому, и наблюдаемое уменьшение плотности породы по направлению к востоку: в районе Нарвы, где распространяются самые высокодисперсные разновидности глин, объемные

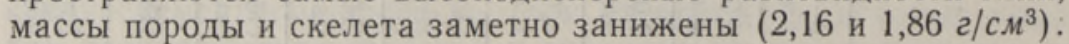

Плотность глин люкатиской свиты значительно меняется как пространственно, так и с глубиной. В предглинтовой зоне, где глины покрыты лишь шлейфом четвертичных наносов и время от времени смачиваются морской или дождевой водой, верхняя часть люкатиских глин мощностью $2,0-2,5$ м характеризуется заниженными значениями объемной массы и объемной массы скелета: в окрестностях Тойла, Азери и

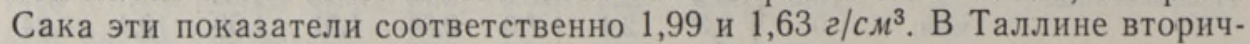
ные процессы почти не улавливаются - объемная масса глин верхней

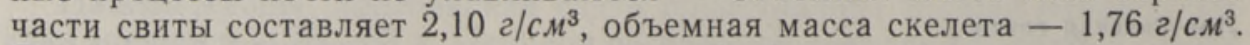
В пределах карбонатного плато, где кембрийские глины перекрываются ордовикскими породами, признаки вторичного разуплотнения не обнаруживаются или выражены очень слабо в верхних слоях люкатиской свиты $(0,2-0,3 \mu)$.

Показатели пористости изученных глин дают в общих чертах ту же информацию, которую дает плотность породы: пористость невыветрелых глин обеих свит весьма близка, в разуплотненных разновидностях она заметно возрастает. 
Консистенция и водные свойства кембрийских глин

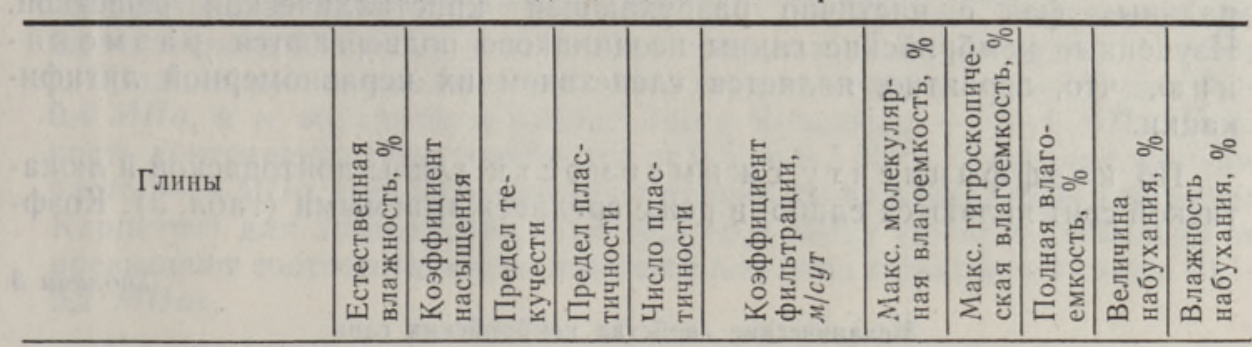

\section{Люкатиская свита}

Разуплотненные

$\begin{array}{llllllll}\text { выветрелые } \quad \bar{x} & 21,1 & 0,95 & 0,42 & 0,24 & 0,19 & 10 \cdot 10^{-6}\end{array}$ $\begin{array}{lllllll}\text { мин. } & 15,3 & 0,70 & 0,25 & 0,16 & 0,06 & 2,7 \cdot 10^{-6} \\ \text { макс. } & 29,6 & 1,00 & 0,55 & 0,31 & 0,30 & 9,3 \cdot 10^{-12}\end{array}$

$\begin{array}{lllllll}\text { Неизмененные } \quad \bar{x} \quad 15,3 & 0,92 & 0,32 & 0,18 & 0,14 & 13,0 \cdot 10^{-9}\end{array}$ $\begin{array}{lrlllll}\text { мин. } & 6,0 & 0,51 & 0,19 & 0,14 & 0,05 & 1,39 \cdot 10^{-9}\end{array}$

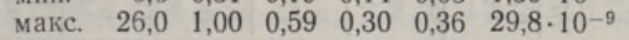

$\begin{array}{rrrrr}- & - & - & 7,8 & 29,8 \\ - & - & - & 5,1 & 5,2 \\ - & - & - & 10,5 & 33,7 \\ 14,8 & 7,0 & 15,7 & 14,2 & 13,8 \\ 10,0 & 6,5 & 14,6 & 0,3 & 3,0 \\ 23,0 & 7,9 & 17,6 & 33,3 & 23,8\end{array}$

Лонтоваская свита

$\begin{array}{lllllllllll}\text { Нензмененные } \quad \bar{x} \quad 14,6 & 0,95 & 0,43 & 0,25 & 0,17 & 4,63 \cdot 10^{-9} & 17,3 & 8,1 & 13,8 & 10,5 & 18,2\end{array}$

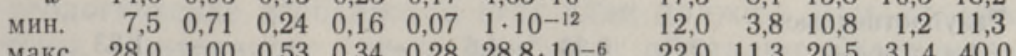

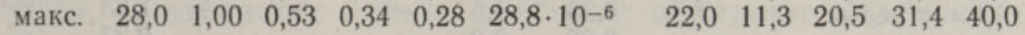

Естественная вл а жнсть находится также в тесной корреляции с плотностными характеристиками. Лонтоваские глины на значительной глубине отличаются наименьшей влажностью (табл. 2). Наиболее часто влажность этих пород находится в пределах $12-14 \%$. В окрестностях Нарвы лонтоваские глины более увлажнены (в среднем 16,9\%).

Естественная влажность плотной, невыветрелой части глин люкатиской свиты мало отличается от влажности вышеприведенных глин. В то же время верхние слои люкатиской свиты, являющиеся водоупором для вендо-кембрийского водоносного горизонта, содержат влаги примерно в 1,4 раза больше, чем нижние.

Консистенция плотных кембрийских глин всегда твердая, а выветрелых и вторично измененных разностей - пластичная. Сравнительно высокая пластичность лонтоваских глин по сравнению с пластичностью люкатиских обусловлена бо́льшим содержанием глинистых частиц. По значениям пластичности $57 \%$ изученных лонтоваских глин принадлежит к глинам, $43 \%$ - к суглинкам. Из люкатиских глин лишь $38 \%$ относится к глинам, $57 \%$ - к суглинкам. Сопоставление этих данных с данными гранулометрического состава обнаруживает, что по пластичности кембрийские глины относятся к более легким типам грунтов, которые характеризуются пониженной активностью при взаимодействии с водой.

Максимальная молекулярная влагоемкость лонтоваских $(16-17 \%)$ и люкатиских $(14 \%)$ глин умеренная, полная в ла гоемкость близка к естественной влажности, а коэффициент фильтр ции очень незначителен (табл. 2). Судя по величине и влажности набухания, кембрийские глины довольно устойчивы при взаимодействии с водой. Исключение составляют отдельные прослои глин на различных глубинах, и особенно, в верхних частях люкатиской свиты, обладающие аномально сильной набухаемостью при влажности набухания до $40 \%$. Так как увеличение влажности набухания сопровож- 
дается одновременным увеличением влажности на пределе пластичности, то можно предполагать возникновение в этих глинах некоторых минеральных фаз с частично разбухающей кристаллической решеткой. Изученные кембрийские глины неодинаково подвергаются р аз моканию, что, вероятно, является следствием их неравномерной литификации.

По коэффициен ту с жи м а е м с т и глины лонтоваской и люкатиской свит являются слабо- и реже среднесжимаемыми (табл. 3). Коэф-

Таблица 3

Механические свойства кембрийских глин

\begin{tabular}{|c|c|c|c|c|c|c|c|c|c|}
\hline Глины & 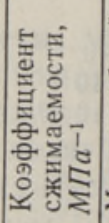 & 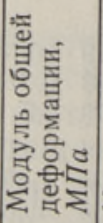 & 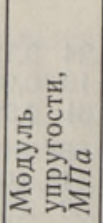 & 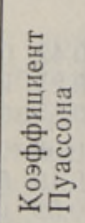 & 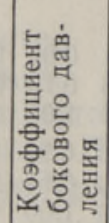 & 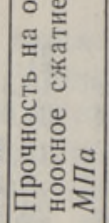 & 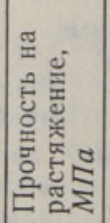 & 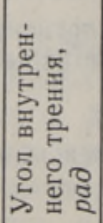 & 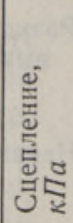 \\
\hline
\end{tabular}

\section{Люкатиская свита}

Разуплотненные выветрелые

$\begin{array}{crr}\bar{x} & 0,23 & 4,6 \\ \text { мин. } & 0,06 & 2,0 \\ \text { макс. } & 0,50 & 11,0 \\ \bar{x} & 0,05 & 12,5 \\ \text { мин. } & 0,01 & 4,0 \\ \text { макс. } & 0,13 & 35,0\end{array}$

$\begin{array}{rrr}\bar{E} & \overline{-} & - \\ \overline{-} & \overline{-} & \overline{-} \\ 9,8 & 0,19 & 0,25 \\ 5,4 & 0,11 & 0,12 \\ 14,2 & 0,28 & 0,39\end{array}$

1,83
0,27
4,40
2,12
0,36
7,23

$\begin{array}{rrr}- & 0,33 & 28 \\ - & 0,16 & 0 \\ - & 0,60 & 94 \\ 0,14 & 0,40 & 12 \\ 0,10 & 0,21 & 0 \\ 0,18 & 0,78 & 140\end{array}$

Лонтоваская свита

Неизмененные

$\begin{array}{crrrrr}\vec{x} & 0,05 & 14,9 & 22,2 & 0,23 & 0,30 \\ \text { мин. } & 0,01 & 4,0 & 3,0 & 0,11 & 0,12 \\ \text { макс. } & 0,31 & 58,0 & 34,0 & 0,32 & 0,43\end{array}$

$\begin{array}{lll}3,40 & 0,56 & 0,53 \\ 0,30 & 0,03 & 0,33 \\ 9,70 & 1,15 & 0,78\end{array}$

105

7

фициент сжимаемости лонтоваских глин при вертикальной нагрузке 0,4-0,6 MПа находится обычно в интервале $0,04-0,07 M M^{-1}$. Сжимаемость люкатиских глин более изменчива. Самые уплотненные и малосжимаемые глины находятся в пределах карбонатного плато (Ору, Ярвекюла, Вяо), где даже максимальные значения коэффициента сжимаемости не превышают $0,01 M \Pi a^{-1}$. В пределах предглинтовой полосы глины люкатиской свиты либо мало- (Виймси), либо среднесжимаемы (Таллин, Азери, Тойла, Сака) с коэффициентом сжимаемости 0,13$0,24 M \Pi a^{-1}$. При этом разуплотненная часть характеризуется коэффициентом сжимаемости порядка $0,2-0,4$, в отдельных случаях $0,5 \mathrm{M \Pi}^{-1}$.

Рассчитанный модуль обще й де форм ции колеблется в пределах 4-60 МПа, в зависимости от литологического характера породы, трещиноватости и, очевидно, от способа отбора проб (Ломтадзе, 1958). Резко заниженные значения модуля характерны для увлажненных глин люкатиской свиты $(2-10 \mathrm{M \Pi a})$. Модули деформации по данным полевых опытных нагрузок близки вышеприведенным: со штампом площадью $5000 c \mu^{2}$ при нагрузке $0,1 M \Pi a$ составляют 43 МПа, при 0,35 $M \Pi a-$ 23 МПа. Предел пропорциональности составляет $1,1 \mathrm{MПа}$, а полное разрушение породы происходит при нагрузке 1,33 МПа.

Модуль упругости, определенный по цилиндрическим пробам

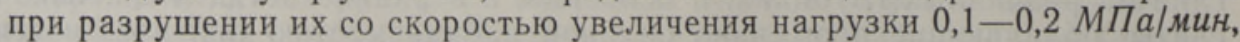
составляет лишь 3-34 MПа, но все же колеблется в значительных пре- 
делах. Незакономерно колеблются и значения коэффициентов бокового давления и Пуассона (табл. 3). В соответствии с повышенной плотностью кембрийских глин их пр очность также значительна. Однако конкретные значения меняются в заметных пределах. Так, люкатиские глины г. Таллина при одноосном сжатии характеризуются прочностью 0,3$0,4 M \Pi a$, а те же глины в районе Вяо и Ярвекюла - 3-4 МПа. Прочность лонтоваских глин колеблется от 0,5 до 9,7 МПа, составляя наиболее часто $2-5$ МПа. При этом значения прочности на растяжение (по методу Карпетро) для лонтоваских глин $(0,5-0,6 \mathrm{M \Pi a})$ также в несколько раз превышают соответствующие значения для глин люкатиской свиты $(0,1-$ $0,2 M \Pi a)$.

С опротивление сдвигу для лонтоваских глин характеризуется повышенными значениями сцепления (в среднем 100 кПа) и заниженными значениями угла внутреннего трения (в среднем 0,53 рад). Для глин люкатиской свиты эти значения несколько занижены (табл. 3).

Таким образом, основные физико-механические свойства кембрийских глин меняются иногда в значительных пределах - в зависимости от особенностей состава этих пород и очень часто от доступности их агентам гипергенеза. Особенно это касается люкатиских глин, которые в зависимости от расположения в разрезе могут быть послойно разуплотнены или даже разжижены. При проектировании строительных оснований инженерно-геологические особенности этих глин должны быть дополнительно изучены. Лонтоваские глины, наоборот, обладают более выдержанными в пространстве свойствами и имеют в целом хорошую несущую способность, являясь тем самым надежным основанием для большинства видов сооружений. Поэтому для предварительной оценки их свойств в инженерно-геологической практике можно руководствоваться представленным выше материалом.

\section{ЛИТЕРАТУРА}

Л о м т а д з е В. Д. Физико-механические свойства нижнекембрийских глин северо-западной окраины Русской платформы. - Зап. Ленингр. горн. ин-та, 1958, № 34, вып. 1, с. 154-188.

Л о м т а дз е В. Д. Инженерная геология. Инженерная петрология. Л., 1970.

Л о ог А., М е н с К., М ю ю р и с е п п К. О границе лонтоваской и пиритаской свит нижнего кембрия Прибалтики. - Изв. АН ЭстССР. Сер. физ.-мат. и техн. наук, 1966, т. 15 , № 2 , с. $271-276$.

М ен с К. А., П и р р у с Э. А. Базальный конгломерат люкатиской свиты нижнего кембрия Эстонии. - В кн.: Геология кристаллического фундамента и осадочного чехла Прибалтики. Рига, 1975 , с. $132-143$.

М ен с К., Пи р р у с Э. Стратотипические разрезы кембрия Эстонии. Таллин, 1977.

П и р р ус Э. Закономерности распределения глинистых минералов в вендских и кембрийских отложениях Восточной Эстонии. - Изв. АН ЭстССР. Хим. Геол., 1970, т. 19 , № 4 , с. $322-333$.

O 11 i, V. Eesti NSV pinnastest. - Ehitusgeoloogiline kogumik I. Tallinn, 1962, 1k. 14-22.

P ir r u s, E. Mida teame sinisavist. - Eesti Loodus, 1973, nr. 11, 1k. 646-653.

Ннститут геологии

Академии наук Эстонской ССР
Поступила в редакцию 13/IV 1978 


\section{E. PIRRUS, Leili SAARSE}

\section{POHJA-EESTI KAMBRIUMI SAVIDE FUUSIKALIS-MEHAANILISED OMADUSED}

Artiklis on esitatud Põhja-Eesti avamusalal paljanduvate alamkambriumi savide olulisemad füüsikalis-mehaanilised näitajad. On juhitud tähelepanu asjaolule, et lükati kihistu ülemise, murenenud osa savi tihedus ja nihkeparameetrid on väiksemad ning kokkusurutavus suurem kui sama kihistu murenemata osa savi vastavad näitajad (tab. 1, 2 ja 3).

\section{E. PIRRUS, Leili SAARSE}

\section{GEOTECHNICAL PROPERTIES OF THE CAMBRIAN CLAYS IN NORTH ESTONIA}

The present paper deals with the results of research into the geotechnical properties of Cambrian formations in North Estonia. Authors have generalized abundant information that has been received during the recent $10-15$ years in connection with intensive engineering-geological investigation of soils in Estonia. The description and short stratigraphical characterization of the Lükati and Lontova formations are presented. It has been pointed out that the uppermost strata of the Lükati formation are often weathered and their geotechnical properties are correspondingly more unsuitable as compared with the unweathered Lükati and Lontova formations. The latter have a higher bearing capacity.

Tables contain the following arithmetical means: minimum and maximum numbers of the weathered Lükati and unweathered Lükati and Lontova formations: granulometrical fractions, specific gravity, unit weight, dry unit weight, porosity and void ratio (Table 1); water content, degree of saturation, liquid limit, plastic limit, plasticity index, coefficient of permeability, maximum molecular water absorbing capacity, hygroscopic capacity, absolute moisture capacity, swelling, and moisture of swelling (Table 2); coefficient of compressibility, modulus of deformation, modulus of elasticity, Poisson's ratio, coefficient of lateral compression, cylinder strength, tensile strength, angle of internal friction and cohesion (Table 3 ). 